\title{
Preparedness of Caregivers of Cancer Patients to Provide Care
}

\author{
(D) Hatice KARABUGA YAKAR, (1) Sıdıka OĞUZ, BDelgin TAVŞAN, (1) Cansu ER, \\ (D) Hüseyin Murat ÇATALBAŞ, (1) Merve SARI
}

Department of Nursing, Marmara University, Faculty of Health Sciences, İstanbul-Turkey

\begin{abstract}
OBJECTIVE
This study aimed to investigate the preparedness of individuals providing care for cancer patients.

\section{METHODS}

This cross-sectional descriptive study was carried out with 203 Turkish cancer family caregivers in January-March 2019. The person who spent the longest time with the patient was chosen as the caregiver. The data were collected through face-to-face interviews with the "Caregiver Introductory Form" and "Preparedness Scale of the Family Care Inventory". The scale consisted of eight items, the total score range is $0-32$. Higher scores indicate that the caregiver feels more prepared for their role. Data were evaluated by independent groups t-test and one-way analysis of variance test.
\end{abstract}

\section{RESULTS}

The average age of caregivers was $46.86 \pm 13.8$; most of them were female (64.5\%). Caregivers' mean score of preparedness to provide care was $27.03 \pm 6.05$. Caregivers' with moderate economic status were more ready to provide care than those with poor economic status $(\mathrm{p}<0.05)$. Caregivers who provided care for their patients for less than a year were more ready to provide care compared to those who cared for the patients for one to five years. Likewise, those who provided care for the patients for six to ten years were more ready to provide care than those who provided care for one to five years $(\mathrm{p}<0.05)$.

\section{CONCLUSION}

Caregivers with a modest economic status, those with less than one year of caregiving experience, and those with over five years of caregiving experience feel more ready to provide care.

Keywords: Cancer; care; caregiver; preparedness.

Copyright $\odot$ 2020, Turkish Society for Radiation Oncology

\section{Introduction}

Cancer, along with the health problems it brings, is a disease that requires long-term financial and spiritual struggle.[1] The increasing number of individuals diagnosed with cancer, the prolonged survival of these patients in parallel with the developments in diagnostic and treatment methods, and continued care of cancer patients at home have led family members to take more responsibility for the care of patients. [2-4] Cancer diagnosis and treatment affect both the patient and the family members in all aspects of life and bring physical, social, emotional and economic burdens to the caregiver.[5,6] Caregivers try to maintain the order of their daily life, and at the same time, they have to keep patients' care and treatment under control.[7,8] 
The caregivers are expected to carry out this complex and multidimensional process in the best way, but they are rarely evaluated concerning their preparedness to care.[9-11] Preparedness is being aware of the tasks that they, as caregivers, will have to perform to provide care and their perception of being ready for this. Knowledge and skills competence is essential for preparedness for patient care. [4] In the literature, it was described that caregivers of cancer patients could not obtain adequate information and support from healthcare professionals,[12] and also that caregivers who felt insufficient in providing care suffer from a worsening in their general health, leading to more frequent experiences of problems, including anxiety, depression and social isolation $[8,10,13]$ Because they take on many responsibilities and have needs similar to patients', it is important to evaluate the preparedness of caregivers.[2,13-15]

To our knowledge, there have been no studies in our country, Turkey, that has the preparedness of caregivers of cancer patients to provide care. Planned based on this deficiency, this study was designed to investigate the preparedness of individuals providing care for cancer patients.

\section{Research Questions}

- How ready are the caregivers of cancer patients to provide care?

- Does the preparedness of the caregivers of cancer patients to provide care differ according to the individual characteristics of caregivers?

- Does the preparedness of the caregivers of cancer patients to provide care differ according to characteristics related to caregiving?

\section{Materials and Methods}

\section{Sample and Settings}

This research was planned as a descriptive and cross-sectional study. The universe of this study included individuals who provided care to patients in the outpatient and inpatient setting in the oncology, palliative and chemotherapy clinics of all training and research hospitals located in the Anatolian side of Istanbul. The sample of this study included 203 primary patient relatives who were caregivers of each patient, were over 18 years of age, gave consent and agreed to participate in this study. The person who spent the longest time with the patient was chosen as the caregiver. The data were collected between January and March 2019 through face-to-face interviews with the "Caregiver Introductory Form" and "Preparedness Scale of the Family Care Inventory".

\section{Study Measures}

\section{Caregiver Introductory Form}

Prepared by researchers by reviewing the related literature, the Caregiver Introductory Form consisted of a total of 15 questions, including age, gender, educational status, marital status, economic status, caregiver's health assessment before and after care, whether the caregivers had children, the degree of relativity to the patient, employment status of caregivers, whether the caregivers had dependents, assessment of health before and after care, receiving support in the caregiving process, the most difficult period in the caregiving process, the hours of providing care to the patient, the hours of providing daily care to the patient.

\section{Preparedness Scale of the Family Care Inventory}

The scale was developed in 1986 by Archbold et al. for those who care for elderly people living at home. [16] It was further developed in 1993 and 2000 by revising it to determine the preparedness of caregivers.[17] Preparedness is the perception of being prepared in many aspects involved in the role of providing care. These areas are physical care, emotional support, maintaining home care, and overcoming the stress associated with care. The scale consists of 9 items, including 8 items and an additional item that specifically questions the area the caregivers wanted to be more ready for. The total score obtained from the five-point Likert-type scale varies between 0-32. The higher score obtained from the scale shows that caregivers feel more ready to provide care. The validity and reliability study of the scale for our country was established by Ugur et al. (2017).[18]

\section{Statistical Analysis}

Introductory characteristics were presented with percentiles, averages or medians. Kolmogorov Smirnov analysis was used to check whether the data were normally distributed. In the analysis of normally distributed data, the independent t-test was used to compare two independent groups, one-way ANOVA test was used to determine the difference between more than two independent groups, and the post hoc Tukey test was used to identify the group or groups causing the difference. Level of significance was set at $\mathrm{p}<0.05$.

\section{Results}

The average age of caregivers was $46.81 \pm 13.77,64.5 \%$ were women, $80.3 \%$ were married, $37.9 \%$ were primary school graduates, $51.7 \%$ had middle income, 
$74.9 \%$ were not employed, $81.3 \%$ had children, and $36.9 \%$ were the spouses of patients (Table 1). $62.6 \%$ of the caregivers had no other dependents. $62.1 \%$ rated their own health as good before providing care, while $42.9 \%$ rated their own health as moderate after providing care. $60.6 \%$ of the caregivers did not receive support in the caregiving process. The most difficult period to provide care was the treatment period for $47.8 \%$. The caregivers with less than one year of experience of providing care to the patient represent $55.2 \%$ of the group. $50.7 \%$ of the caregivers provided 19 to 24 hours of care per day (Table 2). 59.1\% of the caregivers stated that they wanted to receive training on symptom management, $57.1 \%$ on adequate and balanced nutrition, and $51.7 \%$ on drug administration (Table 3).

Caregivers' mean score of preparedness to provide care was $27.03 \pm 6.05$ (minimum: 0, maximum: 32 ), and caregivers felt ready to provide care.
When it is examined whether the preparedness of the caregivers varies according to the characteristics related to caregiving, it was seen that those with moderate economic status were more ready to provide care than those with poor economic status $(\mathrm{p}<0.05)$ (Table 1). Caregivers who provided care for their patients for less than a year were more ready to provide care compared to those who cared for the patients for one to five years. Likewise, those who provided care for the patients for six to ten years were more ready to provide care than those who provided care for one to five years $(\mathrm{p}<0.05)$ (Table 2). Besides, caregivers who wanted to receive training on drug administration and symptom management were more ready to provide care than those who did not want to receive training on these topics $(\mathrm{p}<0.05)$ (Table 3$)$.

Preparedness to provide care did not differ significantly by caregivers' gender, marital status, level of education, employment, whether the caregiver had

Table 1 Comparison of caregiver's preparedness scores according to descriptive characteristics

\begin{tabular}{|c|c|c|c|c|c|c|}
\hline \multirow[b]{2}{*}{ Descriptive characteristics } & \multicolumn{6}{|c|}{ Preparedness to provide care } \\
\hline & $\mathbf{n}$ & $\%$ & $\mathbf{M}$ & SD & Te & \\
\hline \multicolumn{7}{|l|}{ Gender } \\
\hline Female & 131 & 64.5 & 27.52 & 5.73 & $t=1.690$ & $p=0.093$ \\
\hline Male & 72 & 34.5 & 26.0 & 6.52 & & \\
\hline \multicolumn{7}{|l|}{ Marital Status } \\
\hline Married & 163 & 80.3 & 26.72 & 6.04 & $t=1.390$ & $p=0.166$ \\
\hline Single & 40 & 19.7 & 28.16 & 6.0 & & \\
\hline Education Status & 77 & 37.9 & 27.20 & 5.73 & & \\
\hline Primary school & 22 & 10.8 & 25.92 & 7.62 & $F=0.556$ & $p=0.734$ \\
\hline Secondary school & 52 & 25.6 & 27.60 & 6.47 & & \\
\hline High school & 20 & 9.9 & 26.24 & 2.98 & & \\
\hline Pre-bachelor's University & 32 & 15.8 & 27.28 & 5.83 & & \\
\hline \multicolumn{7}{|l|}{ Income } \\
\hline${ }^{\mathrm{a} G o o d}$ & 105 & 51.7 & 28.16 & 5.92 & $F=4.047$ & $p=0.019^{*}$ \\
\hline${ }^{\mathrm{b}}$ Moderate & 18 & 8.9 & 26.32 & 6.63 & & $b>c$ \\
\hline 'Poor & 80 & 39.4 & 25.68 & 5.87 & & \\
\hline \multicolumn{7}{|l|}{ Working status } \\
\hline Employed & 51 & 25.1 & 26.96 & 6.32 & $t=0.74$ & $p=0.941$ \\
\hline Unemployed & 152 & 74.9 & 27.04 & 5.98 & & \\
\hline \multicolumn{7}{|l|}{ Having children } \\
\hline Yes & 165 & 81.3 & 26.88 & 5.88 & $t=1.505$ & $p=0.134$ \\
\hline No & 38 & 18.7 & 27.60 & 6.78 & & \\
\hline \multicolumn{7}{|c|}{ Degree of relativity to the patient } \\
\hline Children & 68 & 33.5 & 3.47 & 0.67 & $t=1.689$ & $p=0.092$ \\
\hline Partner & 75 & 36.9 & 3.38 & 0.86 & & \\
\hline Father-Mother & 23 & 11.3 & 3.19 & 0.80 & & \\
\hline Other & 37 & 18.2 & 3.30 & 0.65 & & \\
\hline
\end{tabular}

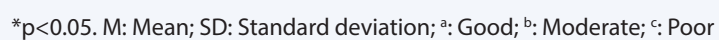


Table 2 Comparison of the caregiver's preparedness scores according to caregiving characteristics

\begin{tabular}{|c|c|c|c|c|c|c|}
\hline \multirow[b]{2}{*}{ Descriptive characteristic } & \multicolumn{6}{|c|}{ Preparedness to provide care } \\
\hline & \multirow[t]{2}{*}{$\mathbf{n}$} & \multirow[t]{2}{*}{$\%$} & \multirow[t]{2}{*}{ M } & \multirow[t]{2}{*}{ SD } & \multicolumn{2}{|c|}{ Test value } \\
\hline \multicolumn{3}{|l|}{ Presence of dependents } & & & & \\
\hline Yes & 76 & 37.4 & 27.12 & 6.29 & $\mathrm{t}=0.272$ & $p=0.786$ \\
\hline No & 127 & 62.6 & 28.16 & 6.00 & & \\
\hline \multicolumn{7}{|c|}{ Self-assessment of health before providing care } \\
\hline Good & 126 & 62.1 & 27.60 & 6.00 & $F=2.801$ & $p=0.063$ \\
\hline Moderate & 65 & 32.0 & 26.32 & 6.12 & & \\
\hline Poor & 12 & 5.9 & 23.76 & 5.18 & & \\
\hline \multicolumn{7}{|c|}{ Self-assessment of health after providing care } \\
\hline Good & 50 & 24.6 & 28.56 & 6.34 & $F=2.153$ & $p=0.119$ \\
\hline Moderate & 87 & 42.9 & 26.56 & 5.54 & & \\
\hline Poor & 66 & 32.5 & 26.40 & 6.36 & & \\
\hline \multicolumn{7}{|c|}{ Receive support for caregiving process } \\
\hline Yes & 80 & 39.4 & 34.50 & 7.40 & $t=0.892$ & $p=0.374$ \\
\hline No & 123 & 60.6 & 33.40 & 7.60 & & \\
\hline \multicolumn{7}{|c|}{ The most difficult period to provide care } \\
\hline Before diagnosis & 15 & 7.4 & 28.32 & 7.59 & $\mathrm{~F}=0.304$ & $p=0.875$ \\
\hline Diagnosis & 48 & 23.6 & 26.80 & 5.16 & & \\
\hline Treatment & 97 & 47.8 & 27.04 & 6.56 & & \\
\hline Recurrence & 24 & 11.8 & 27.12 & 5.60 & & \\
\hline Terminal & 19 & 9.4 & 26.00 & 4.99 & & \\
\hline \multicolumn{7}{|l|}{ Providing care time } \\
\hline aLess than a year & 112 & 55.2 & 27.92 & 5.84 & $F=6.464$ & $\mathrm{p}<.002^{*}$ \\
\hline bone-five year & 80 & 39.4 & 27.28 & 5.80 & & $a>b ; c>b$ \\
\hline cSix year and above & 11 & 5.4 & 30.40 & 7.14 & & \\
\hline \multicolumn{7}{|l|}{ Providing daily time care } \\
\hline 1-6 hour & 59 & 29.1 & 26.72 & 5.96 & $F=0.896$ & $p=0.444$ \\
\hline 7-12 hour & 27 & 13.3 & 28.00 & 5.62 & & \\
\hline 13-18 hour & 14 & 6.9 & 24.88 & 6.62 & & \\
\hline 19-24 hour & 103 & 50.7 & 27.20 & 6.15 & & \\
\hline
\end{tabular}

${ }^{*} \mathrm{p}<0.05$. M: Mean; SD: Standard deviation; ${ }^{a}$ : Less than a year; ${ }^{b}$ : One-five year; ${ }^{c}$ : Six year and above

children, degree of relativity to the patient, presence of dependents, self-assessment of health before and after providing care, the most difficult period to provide care or the duration of daily care $(\mathrm{p}>0.05)$.

\section{Discussion}

In this study, which was carried out to investigate the preparedness of the caregivers of cancer patients, preparedness was affected by economic status and the duration of care. Regardless of the age of the cancer patient, the type and the stage of cancer, the course of the disease, people who care for cancer patients experience economic difficulties. Out-of-pocket costs are incurred because caregivers need an assisting person in childcare and housework, they need to pay for patient's medicines which are not covered by their insurance, buy food supplements, provide means of travel to their appointments, purchase equipment to use at home (wheelchair and oxygen cylinder), take a second opinion for the patient, pay for extra laboratory tests, for hospitalization, dental treatment, ambulatory surgery and home care services.[19-21] Caregivers who feel responsible for the patient's care expenses feel helpless when they cannot fulfill this responsibility.

Many caregivers leave their jobs because of their role.[9] They face decreased job efficiency, loss of employer-based health insurance and other benefits, loss of income, and they go on paid or unpaid leave, work harder to compensate for the loss of income, and work in positions with lower income to comply with the patient's care program.[22-25] As cancer progresses, the 
Table 3 Comparison of the caregiver's preparedness scores according to caregiver's training needs

\begin{tabular}{|c|c|c|c|c|c|c|}
\hline \multirow[b]{2}{*}{ Topics to receive training about providing care } & \multicolumn{6}{|c|}{ Preparedness to provide care } \\
\hline & $\mathbf{n}$ & $\%$ & M & SD & Test & ue \\
\hline \multicolumn{7}{|l|}{ Adequate and balanced nutrition } \\
\hline Yes & 116 & 57.1 & 34.11 & 7.40 & $t=0.866$ & $\mathrm{p}=0.388$ \\
\hline No & 87 & 42.9 & 33.20 & 7.80 & & \\
\hline \multicolumn{7}{|l|}{ Drug administration } \\
\hline Yes & 105 & 51.7 & 35.10 & 7.45 & $t=2.644$ & $\mathrm{p}=0.009^{* *}$ \\
\hline No & 98 & 48.3 & 32.30 & 7.47 & & \\
\hline \multicolumn{7}{|l|}{ Coping with stress } \\
\hline Yes & 90 & 44.3 & 34.10 & 7.28 & $t=0.603$ & $p=0.547$ \\
\hline No & 113 & 55.7 & 33.55 & 7.81 & & \\
\hline \multicolumn{7}{|l|}{ Symptom management } \\
\hline Yes & 120 & 59.1 & 34.60 & 7.67 & $t=1.991$ & $p=0.048^{*}$ \\
\hline No & 83 & 40.9 & 32.51 & 7.20 & & \\
\hline
\end{tabular}

${ }^{*} \mathrm{p}<0.05 ;{ }^{* *} \mathrm{p}<0.01$. M: Mean; SD: Standard deviation

diagnostic and treatment processes of the disease put a further economic burden on the caregiver. If the caregivers lack financial resources and are unable to earn additional income, they become distressed and experience higher concern for the future. Failure to meet caregiving needs due to the economic circumstances and the intensified roles and responsibilities of the caregiver increases their burden and stress, making them feel unready for and unfit to provide care.

Caregivers with less than a year of caregiving experience feel ready to care. We believe that the first reason for this is associated with cultural factors. In our study, most of the caregivers were women and children of the patients. In the Turkish culture, when a disease occurs in the family, children voluntarily and enthusiastically provide care and struggle to overcome all problems, regardless of what troublesome situations their parents will encounter. The second reason is the short-term exposure to the distressing setting of the patient as the time the caregiver provided care is relatively short. Grant et al. (2013) described that caregivers, who were mostly women and unemployed, caring for lung cancer patients felt themselves ready when they first started providing care, but these feelings diminished over time as they started to face problems.[26] Unlike the result of this study, Jacobs et al. (2017) reported that caregivers, who were male and employed at the time of diagnosis and treatment start, felt unready.[6] The gender factor is thought to be effective in the conflicting study results. One of the traditional roles of women in many cultures is caregiving. In case of illness, the woman cares for her parents if she is single and to her husband, if she is married [27] Due to this role imposed on women, caregiving is perceived as a duty that needs to be fulfilled. Not being competent in childcare and housework, less experience with the caregiver role and being employed can be shown as the reason why men do not feel as ready to provide care as women.

Cancers are a group of diseases that change rapidly compared to other chronic diseases, and different symptoms coexist and require the longest time spent for care.[3,28] We believe that the reason why caregivers who have provided care for more than five years feel ready to provide care is that these caregivers have gone through many problems, acquired several skills to overcome problems, accepted this process as a part of daily life and adapted to these circumstances. [29] Caregivers who want to receive training in drug administration and symptom management feel more ready to provide care. The caregivers who feel ready to provide care are aware of their inadequacies and strive to receive training to achieve competence in the care delivery process. Caregivers spend the most troubled periods in the days and weeks immediately following discharge. Caregivers who do not have sufficient knowledge and skills in symptom management, care and treatment particularly feel helpless under these circumstances, which they are not able to manage. Therefore, it is important to plan and implement regular training by healthcare professionals for the caregivers who are to manage the care and treatment of patients not on the day of discharge, but starting as early as on the day the patient is first hospitalized.[30,31] 


\section{Conclusion}

Caregivers with a modest economic status, those with less than one year of caregiving experience and those with over five years of caregiving experience feel more ready to provide care. The economic difficulties of caregivers of cancer patients in Turkey should be identified and efforts to improve the results should be undertaken. Nurses should be aware that "new" caregivers will have difficulties when faced with a problem, while "experienced" caregivers may experience burnout and ignore their own health problems.

Peer-review: Externally peer-reviewed.

Conflict of Interest: The authors declare no conflicts of interest.

Ethics Committee Approval: Ethics committee approval was obtained from the Department of Nursing and the Ethics Committee of the University (Permission no. 61, dated 13.12.2018).

Financial Support: There is no financial support.

Authorship contributions: Concept: H.K.Y Design; H.K.Y.; S.O.; Supervision; H.K.Y.; Funding: None; Materials: H.K.Y., S.O.; C.E.; M.S.; Data collection and processing; H.K.Y.; B.T.; C.E.; H.M.Ç.; M.S.; Data analysis and or interpretation; H.K.Y.; S.O.; Literature search: H.K.Y.; B.T.; C.E.; H.M.Ç.; M.S.; Writing: H.K.Y., S.O.; Critical review: H.K.Y., S.O.

\section{References}

1. World Health Organization, International Agency for Research on Cancer. Available at: https://www.iarc.fr/ featured-news/latest-global-cancer-data-cancer-burden-rises-to-18-1-million-new-cases-and-9-6-million-cancer-deaths-in-2018/ Accessed Oct 10, 2019.

2. Nemati S, Rassouli M, Ilkhani M, Baghestani AR. Perceptions of family caregivers of cancer patients about the challenges of caregiving: a qualitative study. Scand J Caring Sci 2018;32(1):309-16.

3. Huang Y, Wang S, Chen S, Hsu W, Chang M. The experience of spousal caregivers of patients recently diagnosed with cancer in Taiwan. Collegian 2019;26;47784.

4. Mason N, Hodgkin S. Preparedness for caregiving: A phenomenological study of the experiences of rural Australian family palliative carers. Health Soc Care Community 2019;27(4):926-35.

5. Orak OS, Sezgin S. Caregiver Burden in Family Members of Cancer Patients Journal of Psychiatric Nursing 2015; 6(1);33-9.
6. Jacobs JM, Shaffer KM, Nipp RD, Fishbein JN, MacDonald J, El-Jawahri A, et al. Distress is Interdependent in Patients and Caregivers with Newly Diagnosed Incurable Cancers. Ann Behav Med 2017;51(4):51931.

7. Dionne-Odom JN, Demark-Wahnefried W, Taylor RA, Rocque GB, Azuero A, Acemgil A, et al. The selfcare practices of family caregivers of persons with poor prognosis cancer: differences by varying levels of caregiver well-being and preparedness. Support Care Cancer 2017;25(8):2437-44.

8. Muliira JK, Kizza IB, Nakitende G. Roles of Family Caregivers and Perceived Burden When Caring for Hospitalized Adult Cancer Patients: Perspective From a Low-Income Country. Cancer Nurs 2019;42(3):20817.

9. Berry LL, Dalwadi SM, Jacobson JO. Supporting the Supporters: What Family Caregivers Need to Care for a Loved One With Cancer. J Oncol Pract 2017;13(1):3541.

10. Lkhoyaali S, El Haj MA, El Omrani F, Layachi M, Ismaili N, Mrabti $\mathrm{H}$, et al. The burden among family caregivers of elderly cancer patients: prospective study in a Moroccan population. BMC Res Notes 2015;8:347.

11. Aubin M, Vézina L, Verreault R, Simard S, Desbiens JF, Tremblay L, et al. Effectiveness of an intervention to improve supportive care for family caregivers of patients with lung cancer: study protocol for a randomized controlled trial. Trials 2017;18(1):304.

12. LeSeure P, Chongkham-Ang S. The Experience of Caregivers Living with Cancer Patients: A Systematic Review and Meta-Synthesis. J Pers Med 2015;5(4):40639.

13. Henriksson A, Arestedt K. Exploring factors and caregiver outcomes associated with feelings of preparedness for caregiving in family caregivers in palliative care: A correlational, cross-sectional Study. Palliative Medicine 2013;1-8.

14. Caserta M, Utz R, Lund D, Supiano K, Donaldson G. Cancer Caregivers' Preparedness for Loss and Bereavement Outcomes: Do Preloss Caregiver Attributes Matter? Omega (Westport) 2019;80(2):224-44.

15. Hudson P, Aranda S. The Melbourne Family Support Program: evidence-based strategies that prepare family caregivers for supporting palliative care patients. BMJ Support Palliat Care 2014;4(3):231-7.

16. Archbold PG, Stewart BJ. Family caregiving inventory. Unpublished manuscript. Oregon Health Sciences University, School of nursing, Department of Family Nursing, Portland: 1996.

17. Schumacher KL, Stewart BJ, Archbold PG. Mutuality and preparedness moderate the effects of caregiving demand on cancer family caregiver outcomes. Nurs Res 2007;56(6):425-33. 
18. Ugur O, Elcigil A, Aslan D, Paçal S. The Psychometric Properties of the Preparedness Scale of the Family Care Inventory: The Turkish Version. International Journal of Caring Sciences 2017;10(2):657-68.

19. Narang AK, Nicholas LH. Out-of-Pocket Spending and Financial Burden Among Medicare Beneficiaries With Cancer. JAMA Oncol 2017;3(6):757-65.

20. Kent EE, Rowland JH, Northouse L, Litzelman K, Chou WY, Shelburne N, et al. Caring for caregivers and patients: Research and clinical priorities for informal cancer caregiving. Cancer 2016;122(13):198795.

21. Lambert SD, Girgis A. Unmet Supportive Care Needs Among Informal Caregivers of Patients with Cancer: Opportunities and Challenges in Informing the Development of Interventions. Asia Pac J Oncol Nurs 2017;4(2):136-9.

22. Jeon S, Pohl V. Health and work in the family: Evidence from spouses' cancer diagnoses. Journal of Health Economics 2017;52;1(18).

23. Jassem J, Penrod JR, Goren A, Gilloteau I. Caring for relatives with lung cancer in Europe: an evaluation of caregivers' experience. Qual Life Res 2015;24(12):2843-52.

24. Ferrell BR, Kravitz K. Cancer Care: Supporting Underserved and Financially Burdened Family Caregivers. J Adv Pract Oncol 2017;8(5):494-500.

25. Bradley CJ. Economic Burden Associated with Cancer
Caregiving. Semin Oncol Nurs. 2019;35(4):333-6.

26. Grant M, Sun V, Fujinami R, Sidhu R, Otis-Green S, Juarez G, et al. Family caregiver burden, skills preparedness, and quality of life in non-small cell lung cancer. Oncol Nurs Forum 2013;40(4):337-46.

27. Schrank B, Ebert-Vogel A, Amering M, Masel EK, Neubauer M, Watzke H, Zehetmayer S, Schur S. Gender differences in caregiver burden and its determinants in family members of terminally ill cancer patients. Psychooncology 2016;25(7):808-14.

28. Coumoundouros C, Ould Brahim L, Lambert SD, McCusker J. The direct and indirect financial costs of informal cancer care: A scoping review. Health Soc Care Community 2019;27(5):622-36.

29. Maheshwari PS, Mahal RK. Relationship of preparedness and burden among family caregivers of cancer patients in India. Journal of Health, Medicine and Nursing 2016;22:35-44.

30. Hazelwood DM, Koeck S, Wallner M, Anderson KH, Mayer H. Patients with cancer and family caregivers: management of symptoms caused by cancer or cancer therapy at home. HeilberufeScience 2012;3(4):149-58.

31. Hendrix CC, Bailey DE Jr, Steinhauser KE, Olsen MK, Stechuchak KM, Lowman SG, et al. Effects of enhanced caregiver training program on cancer caregiver's self-efficacy, preparedness, and psychological well-being. Support Care Cancer 2016;24(1):327-36. 